\title{
Growth Kinetics in Von Hippel-Lindau-Associated Renal Cell Carcinoma
}

\author{
C.A. Jilg ${ }^{a} \quad$ H.P. Neumann ${ }^{b} \quad$ S. Gläsker ${ }^{c} \quad$ O. Schäfer ${ }^{d} \quad$ P.U. Ardelt ${ }^{a} \quad$ M. Schwardt ${ }^{a}$ \\ W. Schultze-Seemann ${ }^{a}$ \\ Departments of a Urology, ${ }^{b}$ Medicine, ${ }^{c}$ Neurosurgery, and ${ }^{d}$ Radiology, Albert Ludwigs University of Freiburg, \\ Freiburg, Germany
}

\section{Key Words}

Von Hippel-Lindau disease $\cdot$ Kidney cancer $\cdot$ Renal cell carcinoma $\cdot$ Growth kinetics

\begin{abstract}
Objective: To evaluate the growth kinetics of renal cell carcinoma (RCC) in von Hippel-Lindau (VHL) disease in a large trial by $\mathrm{CT} / \mathrm{MRI}$ scan. VHL disease is a multisystemic disorder predisposing to renal cysts and cancer. There is a general assumption that VHL-associated RCC presents slower growth rates than sporadic RCC. Patients and Methods: We describe growth kinetics of 96 renal tumours in $64 \mathrm{VHL}$ patients with analysed germline mutation (54/64 treated, 10/64 active surveillance) over a mean follow-up of 54.9 months. We calculated tumour volume, growth rate, multiplication of tumour volume per year and overall, as well as tumour volume doubling time. Results: The mean growth rate of 96 tumours was $4.4 \mathrm{~mm} /$ year (SD 3.2, median $4.1 \mathrm{~mm} /$ year), mean volume doubling time was 25.7 months (SD 20.2, median 22.2 months). We saw a median 1.4-fold increase in tumour volume per year. At treatment time point, VHL kidneys comprised $39 \%$ tumour and $15.7 \%$ cyst volume fraction. We saw no correlation between tumour size and growth parameters. Conclusion: VHL-associated RCC show large variances in tu-
\end{abstract}

mour growth behaviour. Compared to the literature, in our study the growth rates (mm/year) of RCC in VHL disease did not differ from those of sporadic RCC. Fast tumour growth increases the risk for metastases.

Copyright $\odot 2011$ S. Karger AG, Basel

\section{Introduction}

Von Hippel-Lindau (VHL) disease is a rare autosomal dominant hereditary disorder with multi-organ involvement and variable expression. Although the spectrum of organ manifestations is wide [1], the most common manifestations of VHL disease include haemangioblastoma of the retina and central nervous system, renal cysts and renal cell carcinoma (RCC). The prevalence of VHL disease is about 1 in 31,000-53,000. The responsible gene was identified in 1993 on the short arm of chromosome 3 [24]. Interestingly, somatic mutations of the same gene play an important role in the pathogenesis of sporadic RCCs [5-8]. In recent years, over 1,000 different germline mutations have been described in different databases [9-11]. In $30-40 \%$ of the cases, gene deletions are to a varying extent responsible for manifestation of VHL disease. The remaining groups comprise missense mutations and mu- 
Table 1. VHL patients: tumours, treatments and mutations

\begin{tabular}{lcc}
\hline VHL patients with renal involvement $(\mathrm{n}=64)^{*}$ & \\
\hline VHL mutation & $\mathrm{n}$ & $\%$ \\
\hline Large deletion & 13 & 20 \\
Missense & 19 & 29 \\
Nonsense & 9 & 14 \\
Small deletion & 8 & 12 \\
Small insertion & 3 & 5 \\
Splice & 9 & 14 \\
Unknown & 3 & 5 \\
Overall & 64 & 100 \\
\hline
\end{tabular}

* 86 tumours from 54 patients with 97 interventions and 10 tumours from 10 patients under active surveillance.

tations leading to truncated proteins (small insertion, small deletion, splice, nonsense) [12]. VHL carriers present with RCC about 25 years earlier than patients with sporadic RCC [13]. Furthermore, it is generally assumed that RCC in VHL disease differs in biology from sporadic RCC, which is illustrated by a slower growth rate [1218]. Prognosis mainly depends on the occurrence of RCC and postoperative complications after neurosurgery. Before introduction of modern imaging methods like CT and MRI, $13-42 \%$ of VHL patients died of metastatic RCC [19]. Nephron-sparing surgery (NSS) has become the standard treatment. Most VHL patients will develop RCC recurrence, with multiple microscopic lesions usually already being present in healthy-appearing tissue [20]. Therefore, VHL patients are at high risk for developing end-stage renal failure from treatment of bilateral RCC. However, the question as to proper timing of surgery is as yet unanswered. If the natural history of RCC in VHL patients could be predicted, it would facilitate the decision as to when to start treatment, not only to save patients from receiving redundant treatment, but also to protect them from developing metastases. A crucial step for understanding the biology of VHL renal cancer is to investigate growth patterns, as done in the study presented here. The University Medical Center Freiburg has operated as a centre for VHL patients for more than 20 years now $[4,13,21]$, during which period patients with renal manifestations underwent observation and treatment for RCC. Data were captured on volume fraction of renal cysts and tumour mass in relation to kidney volume, on initial and final tumour volume, growth rate ( $\mathrm{mm} /$ year), multiplication of tumour volume per year and cumula- tive, as well as overall tumour volume doubling time (VDT), and under consideration of underlying germline mutation.

\section{Patients and Methods}

We evaluated $64 \mathrm{VHL}$ patients with renal involvement of whom 54/64 had undergone renal surgery or a radiofrequency thermal ablation procedure for RCC. In 10/64 VHL patients, at least one or more RCC were diagnosed, however at the time of diagnosis an indication for treatment was not yet present. For all patients several CT/MRI scans existed for retrospective description of tumour growth kinetics (table 1). The presence of a VHL germline mutation was known in 61/64 cases. In 3 patients, diagnosis was made based on clinical criteria and family history (table 1 and online suppl. tables S1-6; for all online suppl. material, see www.karger.com/doi/10.1159/000333348). Organ preservation was the primary goal in all first as well as repeat surgeries. An indication for NSS was established once a tumour had reached a diameter of $4 \mathrm{~cm}$. Radical nephrectomy was only performed in cases of functional organ loss or in cases where the parenchyma remnants were not considered worth preserving. For radiofrequency thermal ablation, a tumour size $\geq 2.5 \mathrm{~cm}$ should not have been exceeded and proximity to intestinal structures or large vessels ruled out.

\section{Analysis of Mutations}

10-ml EDTA anticoagulated blood samples were available from each patient for mutation screening of all exons of the VHL gene. Analysis was performed as previously described by Erlic et al. [22]. Genomic DNA from blood samples was extracted using standard methods. Small deletions/insertions or point mutations were identified by DNA sequencing followed by complete mutation screening using PCR/single-strand conformation polymorphism and denaturing high-performance liquid chromatography.

\section{Volumetric Analysis}

Based on the assumption that a description of tumour volume reflects the real tumour burden more precisely and realistically than diameter (mm/year), we calculated the tumour volume of all 96 lesions. For example, doubling the tumour diameter actually means an 8-fold increase in volume. For evaluation of kidney lesions (solid and cystic) by CT/MRI, the digital imaging system IMPAX-EE R20VP1 (AGFA) was applied. When renal tumours were symmetric we used tumour diameter and applied the following formula for volume calculation: $\mathrm{V}\left(\mathrm{mm}^{3}\right)=\Pi \times \mathrm{d}^{3} / 6(\mathrm{~d}=$ diameter).

In cases of asymmetric tumours, if the diameters differed $>5 \mathrm{~mm}$ in three dimensions, the ellipsoid formula was used: $\mathrm{V}\left(\mathrm{mm}^{3}\right)=\mathrm{d} 1 \times \mathrm{d} 2 \times \mathrm{d} 3 \times \Pi / 6(\mathrm{~d}=$ diameter $)[23,24]$. Total kidney volume was also calculated with the ellipsoid formula. The size of cysts and solid tumours in cases of complex renal lesions was evaluated separately.

Volume Fraction of Tumour and Cystic Lesions in Kidney

We used three different quotients $(\mathrm{A}, \mathrm{B}, \mathrm{C})$ to show the volume fraction of cysts and tumours in relation to total kidney volume at the time of treatment: $(\mathrm{A})$ tumour fraction = volume 
Table 2. Growth parameters: 96 tumours from 40 treated patients and 10 patients under active surveillance

\begin{tabular}{lllllll}
\hline Tumours & $\begin{array}{l}\text { VDT, } \\
\text { months }\end{array}$ & $\begin{array}{l}\text { Growth rate, } \\
\mathrm{mm} / \mathrm{year}\end{array}$ & $\begin{array}{l}\text { Initial tumour } \\
\text { diameter, } \mathrm{mm}\end{array}$ & $\begin{array}{l}\text { Final tumour } \\
\text { diameter, } \mathrm{mm}\end{array}$ & $\begin{array}{l}\text { Initial tumour } \\
\text { volume, } \mathrm{mm}^{3}\end{array}$ & $\begin{array}{l}\text { Final tumour } \\
\text { volume, } \mathrm{mm}^{3}\end{array}$ \\
\hline Mean & 25.7 & 4.4 & 19.2 & 37.4 & $7,207.9$ \\
Range & $3.6-103.5$ & $0.5-17.5$ & $3.8-45$ & $12.9-67$ & $28.71-47,712.9$ & $1,124-157,479.1$ \\
Median & 22.2 & 4.1 & 16.0 & 37.2 & $2,144.7$ & $26,956.6$ \\
SD & 20.2 & 3.2 & 10.0 & 14.5 & $11,101.5$ & $39,802.1$ \\
\hline
\end{tabular}

of all tumours/total kidney volume, (B) cyst fraction = volume of all cysts/total kidney volume, and (C) tumour fraction in all renal lesions $=$ volume of all tumours/volume of all kidney lesions.

\section{Cumulative Tumour Volume Multiplication and Volume}

Multiplication per Year

Because the initial diameter, respectively volume, differed in most of the 96 tumours at the time of diagnosis, we equalized the values ( $\mathrm{mm}$ and volume) from the first measurement to 1 (100\%). As a rule, CT/MRI scans were done once a year. If as in some rare cases the time interval deviated from the 12-month follow-up time frame, we calculated the values via linear interpolation.

For calculation of mean tumour volume increase over time we used two different formulas: volume multiplication per year $=$ tumour volume at time point $\mathrm{x} /$ tumour volume 1 year ago; total tumour volume multiplication $=$ final tumour volume/initial tumour volume

\section{Volume Doubling Time}

VDT measured in months was calculated by using the following equation [25-27]:

$$
\mathrm{VDT}=\left(\mathrm{T}-\mathrm{T}_{0}\right) \times \log 2 / \log \mathrm{V}-\log \mathrm{V}_{0}
$$

where $\mathrm{T}_{0}=$ date of initial CT/MRI scan, $\mathrm{T}=$ date of final CT/ MRI scan, $\mathrm{V}_{0}=$ volume $\left(\mathrm{mm}^{3}\right)$ at initial CT/MRI scan, and $\mathrm{V}=$ volume $\left(\mathrm{mm}^{3}\right)$ at final CT/MRI scan.

\section{Statistics}

We used Software Prism 5 GraphPad for calculation. The results were compared between groups using unpaired Student's $t$ test, and the limit of statistical significance was defined as $\mathrm{p}<$ 0.05 . The correlations were analysed by Pearson's coefficient. Linear interpolation of tumour volumes was also done with Prism 5 GraphPad.

\section{Results}

\section{Patients}

The growth of 96 tumours was monitored in $64 \mathrm{pa}-$ tients over a mean follow-up of 54.9 months (median 48 , SD 27.6, range $12-153$ months). The gender ratio (50\%

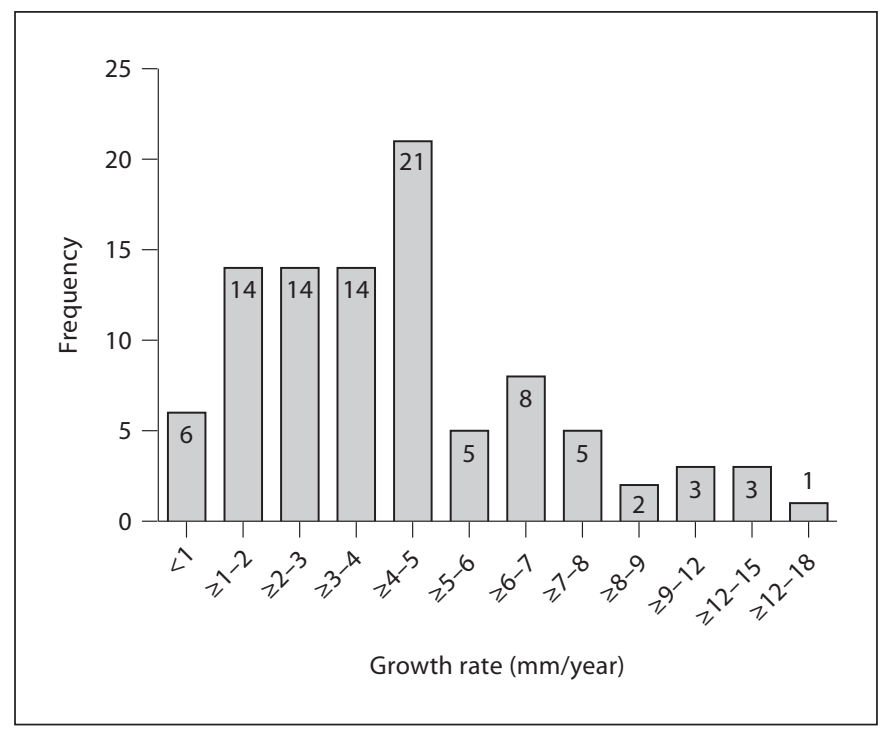

Fig. 1. Frequency distribution of tumour growth in $\mathrm{mm} /$ year $(\mathrm{n}=$ 96). Mean growth rate: $4.4 \mathrm{~mm}$ /year (SD 3.2). Slow kinetic $(<1-3$ $\mathrm{mm} /$ year): $35 \%$ (34/96); moderate kinetic ( $\geq 3-7 \mathrm{~mm} /$ year): $50 \%$ (48/96); fast kinetic ( $\geq 8-17.5 \mathrm{~mm} /$ year): $15 \%$ (14/96).

women $32 / 64$, 50\% men 32/64) was balanced. With respect to the 54 subjects treated, mean age at first treatment was 37 years in males (median 36 years, SD 11.2, range 18-66 years) and 40 years in females (median 38 years, SD 12.5, range 21-73 years). The distribution of underlying germline mutations in 64 patients is shown in table 1.

\section{Growth Parameters}

Growths rates, VDT, initial to final volumes and diameters are shown in table 2, figure 1 and online suppl. table S9. At $<1-3 \mathrm{~mm} /$ year, $35 \%$ (34/96) of the lesions showed slow growth kinetics, $50 \%$ (48/96) of the tumours had moderate growths rates ( $\geq 3-7 \mathrm{~mm} /$ year). Fast-growing characteristics were observed in $15 \%$ (14/96) of the 
Table 3. Overall tumour volume multiplication per year

\begin{tabular}{llllll}
\hline Tumour volume multiplication per year & Year 1 & Year 2 & Year 3 & Year 4 & Year 5 \\
\hline n (tumours) & 96 & 88 & 80 & 55 & 38 \\
Mean & 2.2 & 2.0 & 1.7 & 1.5 & 1.6 \\
Median & 1.6 & 1.5 & 1.4 & 1.3 & 1.4 \\
SD & 1.6 & 1.5 & 0.7 & 0.5 & 0.6 \\
\hline
\end{tabular}

Table 4. Overall cumulative tumour volume multiplication

\begin{tabular}{lllllll}
\hline $\begin{array}{l}\text { Cumulative tumour } \\
\text { volume multiplication }\end{array}$ & Year 1 & Year 2 & Year 3 & Year 4 & Year 5 & Year 6 \\
\hline n (tumours) & 96 & 88 & 8 & 55 & 38 & 25 \\
Mean & 2.2 & 5.2 & 10.2 & 14.1 & 28.7 & 34.6 \\
Median & 1.6 & 2.3 & 3.2 & 4.3 & 6.7 & 11.3 \\
SD & 1.6 & 7.0 & 17.0 & 24.0 & 64.6 & 40.9 \\
\hline
\end{tabular}

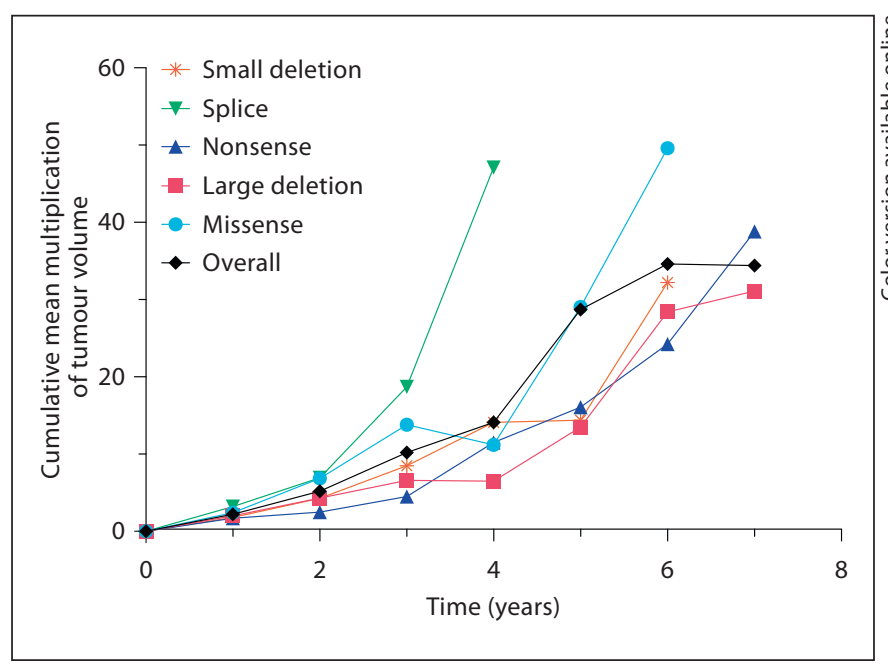

Fig. 2. Mean cumulative tumour volume multiplication = final tumour volume/initial tumour volume. Overall and depending on underlying germline mutation.

tumours ( $\geq 8-17.5 \mathrm{~mm} /$ year). VDT was a mean 25.7 months (SD 20.2, median 22.2 months). We saw a large variation in VDT among the 96 tumours (range 3.6-103.5 months). No significant differences were noted in the growth rates ( $\mathrm{mm} /$ year and VDT) of tumours resulting from mutations leading to truncated VHL protein (small deletion, small insertion, splice, nonsense) compared to tumours resulting from large deletions and missense mutation.

\section{Mean Volume Multiplication per Year and Cumulative over Time}

Table 3 and online supplementary table S7 show volume multiplication per year overall and depending on mutation. After 1 year, a median 1.4-fold volume increase was observed (mean 1.8, SD 1.17). Regarding the subcategories of mutations, we saw no significant differences between volume multiplications (online suppl. table S7).

Table 4, figure 2 and supplementary table S8 show a mean cumulative increase in tumour volume $(n=96)$ over a period of 6 years. Regardless of the germline mutation, after 6 years we saw a median 11.3-fold increase in total tumour volume compared to initial volume. Some tumours stayed approximately the same size in the period under observation, while others showed a dramatic volume increase, meaning that tumour growth differed widely. Standard deviations were high and we therefore reported no significant differences in total volume multiplication when subdividing patients according to germline mutation type.

\section{Volume Fraction of Tumour and Cystic Lesion in \\ Kidney}

Detailed data on quotients (A, B, C) for description of volume fraction are given in table 5 . At treatment time point (97 interventions), VHL kidneys comprised 39\% tumour and $15.7 \%$ cyst volume fraction. Tumour volume fraction in the total number of lesions (cysts and tumours) investigated was mean $77.1 \%$. We found no differences when we looked for different underlying mutations. 
Table 5. Percent of volume fraction of cysts and tumours at time point of intervention

\begin{tabular}{llcc}
$\begin{array}{l}\text { Tumour and cyst fraction } \\
\text { (97 interventions) }\end{array}$ & $\begin{array}{l}\text { Tumour fraction in } \\
\text { kidney volume (A) }\end{array}$ & $\begin{array}{l}\text { Cyst fraction in kidney } \\
\text { volume (B) }\end{array}$ & $\begin{array}{l}\text { Tumour fraction in all } \\
\text { kidney lesions (C) }\end{array}$ \\
\hline Mean & $39.4 \%$ & $15.7 \%$ & $77.1 \%$ \\
Median & $33.1 \%$ & $5.7 \%$ & $84.2 \%$ \\
SD & $30.0 \%$ & $21.9 \%$ & $23.8 \%$ \\
\hline
\end{tabular}

\section{Mean Numbers of Treated Tumours per Kidney}

The mean number of tumours treated per kidney in 97 surgeries was 4.7 (median 3, SD 5.5, range 1-33; table 6). In cases of missense mutation (30 kidneys, mean 43.1, SD 4.1) the number of tumours removed was significantly ( $\mathrm{p}$ value $=0.035$, CI $0.2-6.08$ ) lower than the number of tumours resulting from mutations leading to truncated protein (39 kidneys, mean 6.3, SD 7.1). We saw no differences between large deletions and mutations leading to truncated proteins.

\section{Tumour Size and Mutation}

Data on the growth kinetics of the 96 tumours investigated revealed a mean final tumour size of $37.4 \mathrm{~mm}$ (SD 15.5, median 37.2, range 12.9-67) (table 2, online suppl. table S9). Classification of patients according to underlying germline mutation did not reveal a significant difference in tumour size.

\section{Correlations}

We found no strong correlations regarding VDT versus initial diameter $(\mathrm{r}=0.4)$ and VDT versus initial volume $(\mathrm{r}=0.3)$. Furthermore, correlation of growth rate $(\mathrm{mm} /$ year) versus diameter initial $(r=0.04)$ and growth rate $(\mathrm{mm} /$ year) versus volume initial was not strong $(\mathrm{r}=0.06)$.

\section{Tumours in Patients Who Failed to Comply with the} Surveillance Protocol

5/64 patients did not follow the strict surveillance protocol and developed metastases. In 1 case (1/64), VHL diagnosis was made by detection of metastases from RCC. The growth rate of the largest tumours found in patients with metastasis (mean $8.8 \mathrm{~mm} /$ year, $\mathrm{n}=6$ ) was significantly higher than that of the largest tumours found in patients without metastasis (mean $4.9 \mathrm{~mm} / \mathrm{year}$, $\mathrm{n}=58)(\mathrm{p}$ value $=0.015$, CI $0.78-7)$. The mean final diameter of the largest tumours in patients with metastases $(57.3 \mathrm{~mm}, \mathrm{n}=6$ ) was significantly greater than that of the largest tumours in patients without metastases $(37.4 \mathrm{~mm}$,
Table 6. Number of treated tumours overall and depending on mutation

\begin{tabular}{lllll}
\hline \multirow{2}{*}{ Number of treated tumours per kidney } & \multicolumn{3}{c}{ (97 interventions) } \\
\hline mutation & mean & median & SD & range \\
\hline Missense & 3.1 & 1 & 4 & $1-19$ \\
Nonsense & 4.5 & 3.5 & 3.9 & $1-13$ \\
Large deletion & 4.4 & 3 & 3.4 & $1-17$ \\
Small deletion & 3.9 & 3.5 & 1.9 & $1-7$ \\
Small insertion & 1 & 1 & 0 & $1-1$ \\
Splice & 9.17 & 5.5 & 9 & $1-33$ \\
Unknown & 3.3 & 2 & 2.6 & $1-7$ \\
Overall & 4.7 & 3 & 5.5 & $1-33$ \\
\hline
\end{tabular}

$\mathrm{n}=58)(\mathrm{p}$ value $=0.0041$, CI 6.62-33.22). We also observed differences in the volume of tumours detected in patients with and without metastases. The mean volume of the largest tumours in patients with metastases was $107,100 \mathrm{~mm}^{3}(\mathrm{n}=6)$, and thus significantly larger than that of the largest tumours detected in patients without metastases $\left(40,884 \mathrm{~mm}^{3}, \mathrm{n}=58\right)(\mathrm{p}$ value $=0.0009, \mathrm{CI}$ $28,728-103,703)$.

\section{Discussion}

VHL patients are at high risk for end-stage renal failure and from recurrent treatment of bilateral RCC. More than 3 NSS on each kidney present a risk of irreversible organ damage and the need for subsequent dialysis. It is universally accepted that the biology of VHL-associated RCC differs from that of sporadic RCC, as illustrated by a slower growth rate [12-18]. Based on CT/MRI scans, we evaluated in a large trial renal tumour growth rates in VHL disease overall and under consideration of underlying germline mutation. We show that the growth rate of RCC in VHL disease is neither slower nor faster than in sporadic RCC. 
In fact in both groups it is only the attending physicians who make fundamental distinctions in treatment of RCC. To start with, knowledge of the family history means renal lesions are diagnosed earlier in VHL patients than in sporadic cases. Because the overall number of repeat surgeries per kidney is limited in VHL disease due to frequency of local recurrence, we opt for active surveillance for as long as the tumour has not crossed the threshold size for surgery. Hence, in VHL disease, a number of small tumours are monitored over a long period of time. However, we would only adopt this strategy in selected cases to treat patients with sporadic RCC. Sporadic RCC is diagnosed at 60-64 years of age in most cases [28] and urgent surgery is usually recommended. Thus, it is evident that we are perhaps looking at the same tumours but in different collectives and from a different point of view.

Observation and analysis of RCC growth in VHL disease is rarely undertaken and often limited because of patient numbers and follow-up. In 1992, Choyke et al. [15] first reported on CT follow-up of 42 solid lesions in 28 patients ( 2.4 years' follow-up) a mean tumour growth rate of $16 \mathrm{~mm} /$ year. In contrast to data on sporadic RCC in today's literature (mean $2.8 \mathrm{~mm} /$ year) $[29,30]$, Choyke et al. [15] documented quite fast-growing, aggressive-appearing tumours. Neumann et al. [13] studied 26 RCC lesions in VHL patients over a 5-year follow-up and described a mean growth rate of $2.6 \mathrm{~mm}$ /year. The growth rate of tumours in VHL disease was compared to data provided by Birnbaum et al. [31], who showed $5.2 \mathrm{~mm} /$ year for sporadic RCC. At the time, the authors concluded that tumour growth of RCC in VHL disease is slower than in sporadic RCC. In 2007, Ploussard et al. [18] evaluated the risk of RCC recurrence in VHL disease over a mean follow-up of 100 months in 18 patients (33 kidney surgeries). Recurrence tumours grew at a mean rate of $3.2 \mathrm{~mm} /$ year, which did not differ substantially from that of the primary tumours ( $3.4 \mathrm{~mm} /$ year).

We now present comprehensive data generated on the growth pattern of RCC in VHL disease based on a considerable number of 96 tumours over a mean follow-up of 54.9 months. Apart from a mean VDT of 25.7 months and a mean growth rate of $4.4 \mathrm{~mm}$, we saw a large variance in the growth behaviour of VHL tumours (fig. 1). To simplify variance in growth pattern, we formed three groups for description of growth kinetics: 35\% (34/96) comprised slow-growing tumours ( $<1-3 \mathrm{~mm} /$ year), $50 \%$ (48/96) moderate growing tumours $(\geq 3-7 \mathrm{~mm} /$ year), and $15 \%(14 / 96)$ rapid-growing tumours $(\geq 8-17.5 \mathrm{~mm} /$ year). When calculating the VDT, based on the different tumour growth kinetics, we also observed a large varia- tion (table 2). The literature too confirms that large variances in tumour kinetics are not specific for RCC in VHL disease; rather, sporadic RCC displays a wide spectrum of growth patterns [29].

There is clear evidence that the risk for developing metastases in VHL disease dramatically increases with the rising diameter of RCC $[19,32,33]$. The final diameter and volume of the largest tumours in patients with metastases was significantly greater ( $p$ value $=0.0041$, $p$ val$\mathrm{ue}=0.0009$ ) than of tumours in patients without metastases. The conclusion that tumours with fast growth kinetics harbour an increased risk for metastatic spread is corroborated by the significantly faster growth of tumours in patients with metastasis than in patients without metastatic spread. We must concede, though, that, unfortunately, 5/64 patients failed to observe the recommended follow-up intervals, thus developing metastases because of large tumours. 1/64 patients already presented with metastases at the time of initial VHL diagnoses. We had allocated these 6 cases to the group of tumours showing fast growth kinetics ( $\geq 8-17.5 \mathrm{~mm} /$ year), which encompassed 15\% (14/96 tumours) of all the tumours investigated. Because of the obviously high propensity of fastgrowing tumours to metastasize, on the basis of this knowledge, we suggest that these tumours need to be treated differently in terms of surveillance protocol and treatment. This could for example imply more than one MRI/CT scan per year in order not to miss a critical time point at which to act. Additionally, once a tumour has been classified as 'fast-growing', the diameter threshold for surgical removal should be adjusted downwards.

We did not see a strong correlation between tumour diameter and growth rate. In VHL disease, however, the risk for metastases is probably influenced by both growth rate and tumour size.

In contrast to a few studies on tumour growth kinetics in VHL disease, some studies have described the growth rates of small sporadic RCC based on patients who either refused surgery or were infirm [29, 30,34]. Volpe and Jewett [30] reported a growth rate of $3.08 \mathrm{~mm} /$ year for sporadic RCC, while Chawla et al. [29] reported $2.8 \mathrm{~mm} /$ year. Ozono et al. [25] reported a mean VDT of 20.1 months in 52 sporadic RCC [25]. Like VHL-associated RCC, variation in growth is also present in sporadic RCC, (range 2-4.7 $\mathrm{mm} /$ year) [29]. However, these studies are limited by the short follow-up and the fact that in most cases small lesions (mean diameter $2.6 \mathrm{~cm}$ ) [29] were monitored. Growth characterisation of large sporadic RCC is largely missing in the literature. Therefore, based on a mean final tumour diameter of $3.74 \mathrm{~cm}$, our data 
could have additional relevance for characterisation of the course of large RCC.

Considering our dataset (mean growth rate $4.4 \mathrm{~mm} /$ year, VDT 25.7 months), the assumption should be abandoned that VHL-associated RCC shows substantially different growth characteristics to those of sporadic RCC. This appraisal is not only based on the data presented here but is also supported by the fact that in 74.6-82.4\% of all sporadic RCC cases a mutation exists in a VHL gene $[7,8]$.

Renal carcinoma in VHL disease can occur alone or in combination with complex cystic masses. At the same time, as a rule, simple renal cysts and atypical cysts are present which may subsequently develop into carcinomas [20,35-37]. However, RCC can also arise from non-cystic renal tissue [15]. It has been shown that the majority of cysts in VHL disease grow slowly, and that a direct transition to solid cancer is rare [15]. In our study, at treatment time point (surgery) VHL kidneys comprised 39\% tumour volume and $15.7 \%$ cyst volume in relation to total kidney volume (table 5). We saw no correlation between the content of cysts and tumours with Pearson coefficient $(\mathrm{r}=0.07)$.

Beside VHL classification into type I/IIa/b/c, there is much evidence from several investigations to explain the risk of RCC occurrence in VHL disease. For example, germline mutations leading to truncated protein appear to confer a $40 \%$ risk for RCC manifestation $[38,39]$. Other authors have found that the deletions in the VHL gene extending to the actin regulator HSPC300 appear to lower the risk of RCC [40, 41]. Nonsense and frameshift mutations appear to have a higher age-related risk for RCC than missense [42]. Furthermore, there is a general assumption that mutations within the HIF-binding domain lead to a higher occurrence to RCC [43]. The theory that mutations in distinct cluster regions for missense mutation (MCR) enhance the risk for RCC was shown by Gallou et al. [38] in 2004, but could not be confirmed in other studies [11].
Investigations focussing on explanation and description of the dramatic variation in tumour mass or growth behaviour are largely missing. Here, we attempt to describe in a simple a way growth rates and tumour mass fraction in kidney overall, and with respect to the underlying germline mutation. With this approach and the comparatively low number of cases in germline subcategories, it is ultimately not possible to explain the large variation of tumour burden in VHL renal involvement. Nevertheless, regarding our data, in cases of missense mutations, a significantly ( $\mathrm{p}$ value $=0.035$ ) smaller number of tumours were removed compared to mutations leading to truncated protein. Although the number of cases in the subcategories of mutations was quite low, growth rates differed between some of the germline mutations. Tumours from splice mutations showed faster growth $(5.6 \mathrm{~mm} /$ year $)$ than cases of nonsense mutation $(2.5 \mathrm{~mm} /$ year $)$ ( $\mathrm{p}$ value $=0.0048$, CI $1-5.1)$. Concerning VDT, the same constellation was observed for both splice and nonsense mutations (VDT splice 14.7 months, VDT nonsense 35.2 months) ( $\mathrm{p}$ value $=0.032$, CI 2.039). Our observations may reflect the real situation; for the time being, however, they are of a purely descriptive nature.

\section{Conclusion}

VHL-associated RCC shows wide variances in tumour growth behaviour. Compared to the literature, in our study, growth rates of VHL-associated RCC did not differ from those of sporadic RCC. Patients who developed metastases because they failed to comply with the surveillance protocol had significantly larger tumours and faster growing RCC compared to patients without metastases. Although there are hints that some mutations could lead to different growth patterns, knowledge of mutation and radiographic values alone is not sufficient to entirely predict the course of RCC.

\section{References}

-1 Karsdorp N, Elderson A, Wittebol-Post D, Hene RJ, Vos J, Feldberg MA, et al: Von Hippel-Lindau disease: new strategies in early detection and treatment. Am J Med 1994;97: 158-168.

-2 Gnarra JR, Glenn GM, Latif F, Anglard P, Lerman MI, Zbar B, et al: Molecular genetic studies of sporadic and familial renal cell carcinoma. Urol Clin North Am 1993;20: 207-216

- 3 Latif F, Tory K, Gnarra J, Yao M, Duh FM, Orcutt ML, et al: Identification of the von Hippel-Lindau disease tumor suppressor gene. Science 1993;260:1317-1320.

$\checkmark 4$ Neumann HP, Wiestler OD: Clustering of features of von Hippel-Lindau syndrome: evidence for a complex genetic locus. Lancet 1991;337:1052-1054.

5 Whaley JM, Naglich J, Gelbert L, Hsia YE, Lamiell JM, Green JS, et al: Germ-line mutations in the von Hippel-Lindau tumor-suppressor gene are similar to somatic von HippelLindau aberrations in sporadic renal cell carcinoma. Am J Hum Genet 1994;55:1092-1102. 
6 Beroukhim R, Brunet JP, Di Napoli A, Mertz KD, Seeley A, Pires MM, et al: Patterns of gene expression and copy-number alterations in von Hippel-Lindau disease-associated and sporadic clear cell carcinoma of the kidney. Cancer Res 2009;69:4674-4681.

7 Nickerson ML, Jaeger E, Shi Y, Durocher JA, Mahurkar S, Zaridze D, et al: Improved identification of von Hippel-Lindau gene alterations in clear cell renal tumors. Clin Cancer Res 2008; 14:4726-4734.

$\checkmark 8$ Young AC, Craven RA, Cohen D, Taylor C, Booth C, Harnden P, et al: Analysis of VHL gene alterations and their relationship to clinical parameters in sporadic conventional renal cell carcinoma. Clin Cancer Res 2009; 15:7582-7592.

$\checkmark 9$ Stenson PD, Ball EV, Mort M, Phillips AD, Shiel JA, Thomas NS, et al: Human Gene Mutation Database (HGMD): 2003 update. Hum Mutat 2003;21:577-581.

10 Beroud C, Joly D, Gallou C, Staroz F, Orfanelli MT, Junien C: Software and database for the analysis of mutations in the VHL gene. Nucleic Acids Res 1998;26:256-258.

-11 Nordstrom-O’Brien M, van der Luijt RB, van Rooijen E, van den Ouweland AM, MajoorKrakauer DF, Lolkema MP, et al: Genetic analysis of von Hippel-Lindau disease. Hum Mutat 2010;31:521-537.

-12 Maher ER, Neumann HP, Richard S: Von Hippel-Lindau disease: a clinical and scientific review. Eur J Hum Genet 2011;19:617623.

-13 Neumann HP, Bender BU, Berger DP, Laubenberger J, Schultze-Seemann W, Wetterauer U, et al: Prevalence, morphology and biology of renal cell carcinoma in von Hippel-Lindau disease compared to sporadic renal cell carcinoma. J Urol 1998;160:12481254.

14 Verine J, Pluvinage A, Bousquet G, Lehmann-Che J, de Bazelaire C, Soufir N, et al: Hereditary renal cancer syndromes: an update of a systematic review. Eur Urol 2010;58: 701-710.

15 Choyke PL, Glenn GM, Walther MM, Zbar B, Weiss GH, Alexander RB, et al: The natural history of renal lesions in von Hippel-Lindau disease: a serial CT study in 28 patients. AJR Am J Roentgenol 1992;159:1229-1234.

$\checkmark 16$ Joly D, Mejean A, Correas JM, Timsit MO, Verkarre V, Deveaux S, et al: Progress in nephron-sparing therapy for renal cell carcinoma and von Hippel-Lindau disease. J Urol 2011;185:2056-2060.

17 Linehan WM, Grubb RL, Coleman JA, Zbar $\mathrm{B}$, Walther MM: The genetic basis of cancer of kidney cancer: implications for gene-specific clinical management. BJU Int 2005; 95(suppl 2):2-7.

- 18 Ploussard G, Droupy S, Ferlicot S, Ples R, Rocher L, Richard S, et al: Local recurrence after nephron-sparing surgery in von HippelLindau disease. Urology 2007;70:435-439.
19 Walther MM, Choyke PL, Glenn G, Lyne JC, Rayford W, Venzon D, et al: Renal cancer in families with hereditary renal cancer: prospective analysis of a tumor size threshold for renal parenchymal-sparing surgery. J Urol 1999; 161:1475-1479.

20 Walther MM, Lubensky IA, Venzon D, Zbar B, Linehan WM: Prevalence of microscopic lesions in grossly normal renal parenchyma from patients with von Hippel-Lindau disease, sporadic renal cell carcinoma and no renal disease: clinical implications. J Urol 1995;154:2010-2014.

21 Neumann HP, Eggert HR, Scheremet R, Schumacher M, Mohadjer M, Wakhloo AK, et al: Central nervous system lesions in von Hippel-Lindau syndrome. J Neurol Neurosurg Psychiatry 1992;55:898-901.

22 Erlic Z, Hoffmann MM, Sullivan M, Franke G, Peczkowska M, Harsch I, et al: Pathogenicity of DNA variants and double mutations in multiple endocrine neoplasia type 2 and von Hippel-Lindau syndrome. J Clin Endocrinol Metab 2010;95:308-313.

23 Jones TB, Riddick LR, Harpen MD, Dubuis son RL, Samuels D: Ultrasonographic determination of renal mass and renal volume. J Ultrasound Med 1983;2:151-154

24 Emamian SA, Nielsen MB, Pedersen JF, Ytte L: Kidney dimensions at sonography: correlation with age, sex, and habitus in 665 adult volunteers. AJR Am J Roentgenol 1993;160: $83-86$

-25 Ozono S, Miyao N, Igarashi T, Marumo K, Nakazawa H, Fukuda M, et al: Tumor doubling time of renal cell carcinoma measured by CT: collaboration of Japanese Society of Renal Cancer. Jpn J Clin Oncol 2004;34:8285.

26 Lee JY, Kim CK, Choi D, Park BK: Volume doubling time and growth rate of renal cell carcinoma determined by helical CT: a single-institution experience. Eur Radiol 2008; 18:731-737.

27 Zhang J, Kang SK, Wang L, Touijer A, Hricak $\mathrm{H}$ : Distribution of renal tumor growth rates determined by using serial volumetric CT measurements. Radiology 2009;250:137-144.

28 Frank I, Blute ML, Leibovich BC, Cheville JC, Lohse CM, Zincke H: Independent validation of the 2002 American Joint Committee on cancer primary tumor classification for renal cell carcinoma using a large, singleinstitution cohort. J Urol 2005;173:18891892.

29 Chawla SN, Crispen PL, Hanlon AL, Greenberg RE, Chen DY, Uzzo RG: The natural history of observed enhancing renal masses: meta-analysis and review of the world literature. J Urol 2006;175:425-431.

-30 Volpe A, Jewett MA: The natural history of small renal masses. Nat Clin Pract Urol 2005; 2:384-390

-31 Birnbaum BA, Bosniak MA, Megibow AJ, Lubat E, Gordon RB: Observations on the growth of renal neoplasms. Radiology 1990; 176:695-701.
32 Duffey BG, Choyke PL, Glenn G, Grubb RL, Venzon D, Linehan WM, et al: The relationship between renal tumor size and metastases in patients with von Hippel-Lindau disease. J Urol 2004;172:63-65.

>33 Herring JC, Enquist EG, Chernoff A, Linehan WM, Choyke PL, Walther MM: Parenchymal-sparing surgery in patients with hereditary renal cell carcinoma: 10-year experience. J Urol 2001;165:777-781.

>34 Jewett MA, Mattar K, Basiuk J, Morash CG, Pautler SE, Siemens DR, et al: Active surveillance of small renal masses: progression patterns of early stage kidney cancer. Eur Urol 2011;60:39-44.

-35 Kragel PJ, Walther MM, Pestaner JP, FillingKatz MR: Simple renal cysts, atypical renal cysts, and renal cell carcinoma in von Hippel-Lindau disease: a lectin and immunohistochemical study in six patients. Mod Pathol 1991;4:210-214

-36 Solomon D, Schwartz A: Renal pathology in von Hippel-Lindau disease. Hum Pathol 1988;19:1072-1079.

>37 Montani M, Heinimann K, von Teichman A, Rudolph T, Perren A, Moch H: VHL-gene deletion in single renal tubular epithelial cells and renal tubular cysts: further evidence for a cyst-dependent progression pathway of clear cell renal carcinoma in von Hippel-Lindau disease. Am J Surg Pathol 2010;34:806815.

-38 Gallou C, Chauveau D, Richard S, Joly D, Giraud S, Olschwang S, et al: Genotype-phenotype correlation in von Hippel-Lindau families with renal lesions. Hum Mutat 2004;24: 215-224.

-39 Gallou C, Joly D, Mejean A, Staroz F, Martin N, Tarlet G, et al: Mutations of the VHL gene in sporadic renal cell carcinoma: definition of a risk factor for VHL patients to develop an RCC. Hum Mutat 1999;13:464-475.

40 Franke G, Bausch B, Hoffmann MM, Cybulla M, Wilhelm C, Kohlhase J, et al: Alu-Alu recombination underlies the vast majority of large VHL germline deletions: molecular characterization and genotype-phenotype correlations in VHL patients. Hum Mutat 2009;30:776-786.

41 Maranchie JK, Afonso A, Albert PS, Kalyandrug S, Phillips JL, Zhou S, et al: Solid renal tumor severity in von Hippel-Lindau disease is related to germline deletion length and location. Hum Mutat 2004;23:40-46.

$\checkmark 42$ Ong KR, Woodward ER, Killick P, Lim C, Macdonald F, Maher ER: Genotype-phenotype correlations in von Hippel-Lindau disease. Hum Mutat 2007;28:143-149.

-43 Forman JR, Worth CL, Bickerton GR, Eisen TG, Blundell TL: Structural bioinformatics mutation analysis reveals genotype-phenotype correlations in von Hippel-Lindau disease and suggests molecular mechanisms of tumorigenesis. Proteins 2009;77: 84-96. 